\title{
ANALISIS PROPAGASI INDOOR WLAN 802.11g PADA GEDUNG DISHUBKOMINFO KABUPATEN BADUNG
}

\author{
AAN. Agung Indra Prasetya ${ }^{1}$, N. Gunantara ${ }^{2}$, P.K. Sudiarta ${ }^{3}$ \\ ${ }^{123}$ Program Studi Teknik Elektro, Fakultas Teknik, Universitas Udayana \\ Email : agungindraprasetya@gmail.com ${ }^{1}$, nyomangunantara@gmail.com², \\ sudiarta@unud.ac.id ${ }^{3}$
}

\begin{abstract}
ABSTRAK
Dalam prakteknya access point tidak selalu dapat mencakup jarak jangkauan yang maksimal karena perambatan gelombang sinyal dalam ruangan, seperti pemantulan, pembelokkan, maupun penghamburan sinyal. Untuk tujuan optimasi implementasi, maka penelitian ini bertujuan untuk mendapatkan karakteristik kualitas level sinyal dan throughput di gedung Dishubkominfo Kabupaten Badung. Analisis propagasi indoor WLAN IEEE 802.11g dilakukan berdasarkan 3 model pengukuran yaitu tanpa penghalang, penghalang dinding, dan penghalang lantai. Hasil pengukuran signal level tertinggi $-40 \mathrm{dBm}$, sedangkan signal level terendah -85 dBm. Hasil pengukuran throughput maksimal 8,05 Mbps, dari maksimal bandwidth yang telah tersedia yaitu 10 Mbps. Sedangkan coverage area berdasarkan penguji menggunakan software menyesuaikan denah pada gedung, hampir sesuai dengan hasil perhitungan signal level.
\end{abstract}

Kata Kunci : WLAN 802.11g, propagasi indoor, signal level, throughput

ABSTRACT

In practice the access point can not always cover the maximum range of distance due to signal wave propagation in the room, such as reflection, alteration, or scattering of signals. For the purpose of implementation optimization, this study aims to obtain characteristics of signal level quality and throughput at the Dishubkominfo Building of Badung Regency. The indoor propagation analysis of WLAN IEEE 802.11g is based on 3 models of measurement ie without barrier, wall barrier, and floor barrier. The result of the highest signal level measurement is $-40 \mathrm{dBm}$, while the lowest signal level is $-85 \mathrm{dBm}$. Maximum throughput measurement results $8.05 \mathrm{Mbps}$, from the maximum available bandwidth of $10 \mathrm{Mbps}$. While the coverage area based on testers using the software to adjust the floor plan on the building, almost in accordance with the calculation of signal level.

Keywords : WLAN 802.11g, indoor propagation, signal level, throughput

\section{PENDAHULUAN}

Wireless Local Area Network (WLAN) adalah suatu sistem komunikasi data tanpa menggunakan kabel, menggunakan gelombang radio sebagai media komunikasinya. Teknologi WLAN 802.11g merupakan salah satu teknologi tanpa kabel yang menggunakan modulasi OFDM dengan data rate hingga 54 Mbps, walaupun kini telah ada standar baru yang memiliki data rate lebih tinggi, namun standar WLAN IEEE 802.11, masih tetap digunakan oleh para pengguna dan sebagian dari para pengguna tersebut sering memanfaatkan teknologi ini di dalam ruangan (indoor) [1].

Salah satu contohnya implementasi IEEE 802.11 ini adalah pada gedung Dishubkominfo Kabupaten Badung. Implementasi ini bertujuan agar mobilitas pertukaran informasi dapat dilakukan. Karena gedung ini terdiri dari 3 lantai dan banyak ruangan, agar layanan WLAN ini dapat optimal maka perlu dilakukan analisis 
mengenai propagasi indoor WLAN IEEE 802.11g.

Metode analisis yang digunakan adalah terdiri dari perhitungan dan pengukuran signal level, dan throughput yang akan dibandingkan dengan hasil pengukuran yang diukur dengan software pengukuran sesuai dengan kondisi model indoor propagasi yang digunakan yaitu tanpa penghalang, penghalang dinding, dan penghalang lantai. Sedangkan untuk coverage area diukur berdasarkan faktor koreksi antara hasil perhitungan dan hasil pengukuran signal level.

\section{KAJIAN PUSTAKA}

\subsection{WLAN IEEE 802.11g}

Wireless LAN merupakan local area network yang menghubungkan dua komputer atau lebih tanpa menggunakan kabel. WLAN memanfaatkan teknologi modulasi spread spectrum pada gelombang radio sebagai media transmisi untuk dapat berkomunikasi antara device pada area yang terbatas, atau dapat disebut sebagai basic servive set. Hal ini memberikan setiap pengguna suatu mobilitas untuk dapat bergerak di dalam cakupan yang luas dan tetap terhubung pada suatu jaringan [1].

Standar IEEE 802.11g merupakan standar wireless local area network (WLAN) yang bekerja pada frekuensi $2,4 \mathrm{GHz}$ dan performansinya lebih baik dari WLAN $802.11 \mathrm{a} / \mathrm{b}$. Modulasi yang digunakan oleh standar 802.11g adalah Orthogonal Frequency Division Multiplexing (OFDM), yang lebih tahan terhadap interferensi dari gelombang lainnya. Modulasi OFDM dapat melakukan transmisi data yang mampu mencapai data rate $6,9,12,18,24,36,48$ Mbps hingga data rate maksimum 54 Mbps. Selanjutnya untuk maksimum power level, standar $802.11 \mathrm{~g}$ mengikuti tiga standar domain internasional, yaitu standar Amerika, Eropa dan Jepang. Sedangkan untuk receiver sensitivity pada standar WLAN 802.11g, standar ini memiliki sensitivitas penerima sekitar $-88 \mathrm{dBm}$ untuk minimum data rate $6 \mathrm{Mbps}$ dan $-68 \mathrm{dBm}$ untuk maksimum data rate $54 \mathrm{Mbps}$ [2].

\subsection{Propagasi Indoor}

Dalam komunikasi wireless, adanya media transmisi yaitu gelombang radio.
Gelombang radio akan melakukan propagasi untuk mentransmisikan suatu informasi. Propagasi radio didefinikasikan sebagai perambatan gelombang radio di suatu medium yang pada umumnya adalah udara. Propagasi gelombang radio dapat dikatakan ideal jika gelombang yang dipancarkan oleh access point diterima langsung oleh client tanpa melalui suatu hambatan. Pada propagasi indoor terdapat 3 pemodelan yaitu tanpa penghalang, dengan penghalang dinding, dan dengan penghalang lantai [3].

Untuk pemodelan tanpa penghalang, menggunakan persamaan received signal level sebagai berikut.

$R S L=E I R P-L+G r$

dimana :

$R S L$ adalah level kuat sinyal yang diterima (dBm),

$E I R P$ adalah energi yang dikeluarkan oleh sebuah access point atau pemancar ( $\mathrm{dBm})$, $L$ adalah loss (dB),

Gr adalah penguat pada penerima (dB).

Untuk menghitung EIRP, persamaan yang digunakan adalah sebagai berikut.

$E I R P=T_{x}+G_{t}-L_{f}$

dimana :

$T_{x}$ adalah transmit power $(\mathrm{dBm})$,

$G_{t}$ adalah gain antenna $(\mathrm{dBi})$,

$L_{f}$ adalah loss fedder (dB).

Untuk mencari nilai Loss digunakan persamaan berikut.

$L_{(C)}=L_{O}+10 n \log (d)$

dimana :

$L_{O}$ adalah nilai konstanta untuk frekuensi

2,45 GHz (40,2 dB),

$n$ adalah nilai path loss eksponen konstanta untuk frekuensi $2,45 \mathrm{GHz}(4,2)$,

$d$ adalah jarak (m).

Untuk pemodelan penghalang dinding, menggunakan persamaan berikut [4].

$P_{r}=P_{t} G_{t} G_{r}\left(\frac{\lambda}{4 \pi}\right)^{2} d^{-\alpha} 10^{\frac{x \varphi}{10}} \prod_{\mathrm{m}=1}^{\mathrm{M}}\left|\Gamma_{\mathrm{m}}\right|^{2}$

dimana : 
$P_{r}$ adalah received signal level (watt),

$P_{t}$ adalah power transmit bernilai $20 \mathrm{dBm}$ (berdasarkan Tabel 1),

$G_{t}$ adalah transmit antenna gain bernilai 3 $\mathrm{dB}$ (berdasarkan Tabel 1),

$G_{r}$ adalah receive antenna gain bernilai 3 dB (berdasarkan Tabel 1),

$\left(\frac{\lambda}{4 \pi}\right)$ adalah panjang gelombang $(c / f)$,

$d^{-\alpha}$ adalah jarak dari pemancar ke penerima $(\mathrm{m})$,

$10^{\frac{x \varphi}{10}}$ adalah nilai Shadowing,

$\prod_{\mathrm{m}=1}^{\mathrm{M}}\left|\Gamma_{\mathrm{m}}\right|^{2}$ adalah nilai transmisi koefisien dinding $(0,3)$ dan jumlah dinding.

Sedangkan untuk pemodelan penghalang lantai hampir sama dengan pemodelan penghalang dinding, perbedaannya pada nilai transmisi koefisien, dimana dengan asumsi bernilai 0,17 .

$P_{r}=P_{t} G_{t} G_{r}\left(\frac{\lambda}{4 \pi}\right)^{2} d^{-\alpha} 10^{\frac{x \varphi}{10}} \prod_{\mathrm{n}=1}^{\mathrm{N}}\left|\Gamma_{\mathrm{n}}\right|^{2}$

\subsection{Throughput}

Throughput adalah bandwidth aktual yang terukur pada suatu ukuran waktu tertentu dalam suatu hari menggunakan rute internet yang spesifik ketika sedang mengunduh suatu file [5].

Throughput walaupun memiliki satuan yang sama dengan bandwidth yaitu bits per second (bps), tetapi throughput lebih pada menggambarkan bandwidth yang sebenarnya (aktual) pada suatu waktu tertentu dan pada kondisi dan jaringan internet tertentu yang digunakan untuk mengunduh suatu file dengan ukuran tertentu.

Beberapa faktor yang menentukan throughput adalah :
a. Piranti jaringan
b. Tipe data yang ditransfer
c. Topologi jaringan
d. Banyaknya pengguna jaringan
e. Spesifikasi perangkat client/user
f. Induksi listrik dan cuaca.

\subsection{Perangkat Access Point Ubiquiti Unifi}

Access point merupakan perangkat yang menjadi sentral koneksi dari user ke ISP. Access point berfungsi mengkonversikan sinyal frekuensi radio (RF) menjadi sinyal digital yang akan disalurkan melalui kabel, atau disalurkan ke perangkat WLAN yang lain dengan cara dikonversikan ulang menjadi sinyal frekuensi radio.

Spesifikasi dari access point Ubiquiti Unifi dapat dilihat pada Tabel 1 berikut.

Tabel 1 Spesifikasi Wireless Ubiquiti Unifi [6]

\begin{tabular}{|c|c|}
\hline Dimension & $20 \times 20 \times 3.65 \mathrm{~cm}$ \\
\hline Weight & $\begin{array}{r}290 g(430 \mathrm{~g} \text { with } \\
\text { mounting kit) }\end{array}$ \\
\hline Ports & $\begin{array}{r}\text { Ethernet (Auto MDX, } \\
\text { autosensing } \\
10 / 100 M b p s) \\
\end{array}$ \\
\hline Range & $122 m(400 \mathrm{ft})$ \\
\hline Buttons & Reset \\
\hline Antennas & $\begin{array}{r}3 \mathrm{dBi} \text { Omni (supports } \\
2 \times 2 \mathrm{MIMO} \text { with spatial } \\
\text { diversity) }\end{array}$ \\
\hline Wi-FI Standards & $802.11 \mathrm{~b} / \mathrm{g} / \mathrm{n}$ \\
\hline Power Method & $\begin{array}{l}\text { Passive Power over } \\
\text { Ethernet }(12-24 \mathrm{~V})\end{array}$ \\
\hline Power Supply & $\begin{array}{r}24 \mathrm{~V} 0.5 \mathrm{~A} \text { PoE Adapter } \\
\text { included }\end{array}$ \\
\hline $\begin{array}{l}\text { Maximum Power } \\
\text { Consumption }\end{array}$ & $4 W$ \\
\hline Max Tx Power & $20 \mathrm{dBm}$ \\
\hline$B S S I D$ & Up to four per radio \\
\hline Power Save & Supported \\
\hline Wireless Security & $\begin{array}{r}\text { WEP, WPA-PSK, WPA } \\
-T K I P, \text { WPA2 AES, } \\
802.11 i\end{array}$ \\
\hline Certification & $C E, F C C, I C$ \\
\hline Mounting & $\begin{array}{r}\text { Wall/ Ceiling (Kits } \\
\text { included) }\end{array}$ \\
\hline Operating Temperature & $\begin{array}{r}-10 \text { to } 70^{\circ} \mathrm{C}\left(14 \text { to } 158^{\circ}\right. \\
\mathrm{F})\end{array}$ \\
\hline Operating Humidity & $5-80 \%$ Noncondensing \\
\hline
\end{tabular}

\section{METODE PENELITIAN}

Analisis dalam penelitian ini dilakukan dalam beberapa tahapan berikut ini.

a. Melakukan perhitungan signal level dimana pada pemodelan tanpa penghalang dan penghalang dinding client dan AP berada di lantai 2. Untuk pemodelan penghalang lantai, client dilantai 2 sedangkan AP dilantai 3.

b. Melakukan pengukuran signal level berdasarkan jarak antara client dan AP dengan menggunakan kondisi yang sama dengan pengukuran signal level.

c. Melakukan analisis antara pengukuran signal level dengan teori yang digunakan disertai dengan grafik pendukung.

d. Pengukuran throughput dengan kondisi yang sama dengan pengukuran signal level. 
e. Pengukuran coverage dengan metode walktest berdasarkan titik pengukuran signal level.

\section{HASIL DAN PEMBAHASAN}

4.1 Hasil Perhitungan Signal Level

Perhitungan signal level dilakukan pada salah satu lantai di gedung Dishubkominfo yang dianggap mewakili semua pemodelan propagasi indoor. pemodelan tanpa penghalang menggunakan persamaan (1). Langkah pertama adalah menghitung nilai Loss dengan persamaan (3) sebagai berikut.

$L_{(C)}=L_{O}+10 n \log (d)$

$L_{(C)}=40,2+10.4,2 \log (26,54)$

$L_{(C)}=100,005 d B$

Setelah itu mencari nilai EIRP menggunakan persamaan (2) sesuai dengan Tabel 1, berikut penjabarannya.

$E I R P=T_{x}+G_{t}-L_{f}$

$E I R P=20+3-0$

$E I R P=23 \mathrm{dBm}$

Dilanjutkan mencari nilai dari signal level menggunakan persamaan (1).

$$
\begin{aligned}
& R S L=E I R P-L+G r \\
& R S L=23-100,005+3 \\
& R S L=-74,005 \mathrm{dBm}
\end{aligned}
$$

Tahap berikutnya, perhitungan pemodelan penghalang dinding menggunakan persamaan (4) sebagai berikut.

$P_{r}=P_{t} G_{t} G_{r}\left(\frac{\lambda}{4 \pi}\right)^{2} d^{-\alpha} 10^{\frac{x \varphi}{10}} \prod_{\mathrm{m}=1}^{\mathrm{M}}\left|\Gamma_{\mathrm{m}}\right|^{2}$

$P_{r}=20 \cdot 3 \cdot 3\left(\frac{3 \cdot 10^{8} / 2,4 \cdot 10^{9}}{4 \cdot 3,14}\right)^{2} 4,24^{-2} \cdot 1,4193|0,3|^{2}$

$P_{r}=20 \cdot 3 \cdot 3 \cdot 9,904 \times 10^{-5} \cdot 0,055 \cdot 1,4193 \cdot 0,09$

$P_{r}=5,3581 \cdot 10^{-5} \mathrm{~W}=-72,70 \mathrm{dBm}$

Perhitungan nilai sinyal level dengan pemodelan propagasi indoor penghalang lantai menggunakan persamaan (5).

$P_{r}=P_{t} G_{t} G_{r}\left(\frac{\lambda}{4 \pi}\right)^{2} d^{-\alpha} 10^{\frac{x \varphi}{10}} \prod_{\mathrm{n}=1}^{\mathrm{N}}\left|\Gamma_{\mathrm{n}}\right|^{2}$
$P_{r}=20 \cdot 3 \cdot 3\left(\frac{3 \cdot 10^{8} / 2,4 \cdot 10^{9}}{4 \cdot 3,14}\right)^{2} 30,14^{-2} \cdot 1,4193|0,17|^{2}$

$P_{r}=20 \cdot 3 \cdot 3 \cdot 9,904 \times 10^{-5} \cdot 30,14^{-2} \cdot 1,4193 \cdot 1 \cdot 0,0289$

$P_{r}=1,06129 \cdot 10^{-6} \mathrm{~W}=-89,74 \mathrm{dBm}$

Seluruh hasil perhitungan dengan 3 macam kondisi pemodelan propagasi indoor dapat dilihat pada Tabel 2, Tabel 3, dan Tabel 4 berikut.

Tabel 2 Hasil perhitungan signal level kondisi tanpa penghalang

\begin{tabular}{|c|c|c|}
\hline Titik & $\begin{array}{c}\text { Jarak Antara } \\
\text { AP Client } \\
(\mathbf{m})\end{array}$ & $\begin{array}{c}\text { Hasil Perhitungan } \\
\text { (dBm) }\end{array}$ \\
\hline 1 & 26,54 & $-74,005$ \\
\hline 2 & 21,55 & $-70,20$ \\
\hline 3 & 16,56 & $-65,40$ \\
\hline 4 & 11,59 & $-58,90$ \\
\hline 5 & 6,67 & $-48,81$ \\
\hline 6 & 2,12 & $-27,91$ \\
\hline 7 & 3,80 & $-38,58$ \\
\hline 8 & 7,38 & $-50,66$ \\
\hline 9 & 12,02 & $-59,55$ \\
\hline 10 & 16,86 & $-65,73$ \\
\hline 11 & 21,78 & $-70,40$ \\
\hline 12 & 16,56 & $-65,40$ \\
\hline 13 & 17,73 & $-66,65$ \\
\hline 14 & 20,11 & $-68,94$ \\
\hline 15 & 23,33 & $-71,65$ \\
\hline 16 & 27,10 & $-74,38$ \\
\hline 17 & 24,38 & $-72,45$ \\
\hline 18 & 22,46 & $-70,96$ \\
\hline & & \\
\hline
\end{tabular}

Tabel 3 Hasil perhitungan signal level kondisi penghalang dinding

\begin{tabular}{|c|c|c|c|}
\hline \multirow{4}{*}{ Ruang } & $\begin{array}{c}\text { Nilai } \\
\text { Shadowing }\end{array}$ & $\begin{array}{c}\text { Jarak } \\
\text { Antara } \\
\text { AP dan } \\
\text { Client } \\
\text { (m) }\end{array}$ & $\begin{array}{c}\text { Hasil } \\
\text { Perhitungan } \\
\text { (dBm) }\end{array}$ \\
\hline \multirow{4}{*}{ R1 } & 1,4193 & 6,51 & $-72,70$ \\
\cline { 2 - 4 } & 3,3014 & 8,51 & $-71,36$ \\
\cline { 2 - 4 } & 4,3541 & 10,51 & $-71,99$ \\
\cline { 2 - 4 } & 1,7533 & 6,96 & $-72,36$ \\
\cline { 2 - 4 } & 1,2307 & 8,86 & $-75,99$ \\
\hline \multirow{4}{*}{ R2 } & 2,3435 & 10,79 & $-74,91$ \\
\cline { 2 - 4 } & 1,3263 & 3,53 & $-67,68$ \\
\cline { 2 - 4 } & 1,2500 & 4,30 & $-69,64$ \\
\hline \multirow{4}{*}{ R3 } & 10,2831 & 5,70 & $-62,94$ \\
\cline { 2 - 4 } & 6,0718 & 3,51 & $-61,02$ \\
\cline { 2 - 4 } & 2,4088 & 3,89 & $-65,92$ \\
\cline { 2 - 4 } & 7,2178 & 5,09 & $-63,50$ \\
\hline
\end{tabular}




\begin{tabular}{|c|c|c|c|}
\hline & 1,0419 & 5,70 & $-72,88$ \\
\hline \multirow{4}{*}{ R4 } & 1,5928 & 6,44 & $-72,10$ \\
\cline { 2 - 4 } & 1,1428 & 7,58 & $-74,96$ \\
\cline { 2 - 4 } & 1,0842 & 8,26 & $-75,93$ \\
\cline { 2 - 4 } & 2,6385 & 9,18 & $-72,99$ \\
\cline { 2 - 4 } & 2,5034 & 10,15 & $-74,09$ \\
\cline { 2 - 4 } & 2,5168 & 10,91 & $-74,69$ \\
\hline \multirow{4}{*}{ R5 } & 1,5486 & 9,82 & $-75,89$ \\
\cline { 2 - 4 } & 2,1955 & 11,51 & $-75,75$ \\
\cline { 2 - 4 } & 1,5954 & 11,10 & $-76,82$ \\
\cline { 2 - 4 } & 2,8913 & 12,62 & $-75,35$ \\
\cline { 2 - 4 } & 1,3749 & 12,57 & $-78,55$ \\
\cline { 2 - 4 } & 1,9618 & 13,93 & $-77,90$ \\
\hline \multirow{2}{*}{ R6 } & 1,6054 & 13,66 & $-78,60$ \\
\cline { 2 - 4 } & 1,2185 & 14,40 & $-80,25$ \\
\hline
\end{tabular}

Tabel 4 Hasil perhitungan signal level kondisi penghalang lantai

\begin{tabular}{|c|c|c|c|}
\hline Titik & $\begin{array}{c}\text { Nilai } \\
\text { Shadowing }\end{array}$ & $\begin{array}{c}\text { Jarak } \\
\text { Antara AP } \\
\text { dan Client } \\
\mathbf{( m )}\end{array}$ & $\begin{array}{c}\text { Hasil } \\
\text { Perhitungan } \\
\text { (dBm) }\end{array}$ \\
\hline 1 & 1,4193 & 26,24 & $-89,74$ \\
\hline 2 & 3,3014 & 21,54 & $-84,35$ \\
\hline 3 & 4,3541 & 17 & $-81,10$ \\
\hline 4 & 1,7533 & 12,80 & $-82,59$ \\
\hline 5 & 1,2307 & 9,43 & $-81,47$ \\
\hline 6 & 2,3435 & 8 & $-77,24$ \\
\hline 7 & 1,3263 & 9,43 & $-81,14$ \\
\hline 8 & 1,2500 & 10,67 & $-82,48$ \\
\hline 9 & 10,2831 & 13,74 & $-75,52$ \\
\hline 10 & 6,0718 & 17,72 & $-80,01$ \\
\hline 11 & 2,4088 & 22,11 & $-85,95$ \\
\hline 12 & 7,2178 & 17 & $-78,90$ \\
\hline 13 & 1,6039 & 17,72 & $-85,79$ \\
\hline 14 & 1,0419 & 19,72 & $-88,60$ \\
\hline 15 & 1,5928 & 22,67 & $-87,96$ \\
\hline 16 & 1,1428 & 26,24 & $-90,68$ \\
\hline 17 & 1,0842 & 23,74 & $-90,04$ \\
\hline 18 & 2,6385 & 22,11 & $-85,55$ \\
\hline & & & \\
\hline
\end{tabular}

\subsection{Hasil Pengukuran Signal Level}

Pengukuran signal level menggunakan software Wifi Analyzer. Hasil pengukuran signal level ditunjukkan dengan 3 kondisi pemodelan dalam bentuk Tabel 5, Tabel 6, dan Tabel 7.

Tabel 5 Hasil pengukuran signal level kondisi tanpa penghalang

\begin{tabular}{|c|c|c|}
\hline Titik & $\begin{array}{c}\text { Jarak Antara } \\
\text { AP dan Client } \\
\mathbf{( m )}\end{array}$ & $\begin{array}{c}\text { Hasil } \\
\text { Pengukuran } \\
\text { (dBm) }\end{array}$ \\
\hline 1 & 26,54 & -76 \\
\hline 2 & 21,55 & -66 \\
\hline 3 & 16,56 & -57 \\
\hline 4 & 11,59 & -52 \\
\hline 5 & 6,67 & -43 \\
\hline 6 & 2,12 & -40 \\
\hline 7 & 3,80 & -40 \\
\hline 8 & 7,38 & -45 \\
\hline 9 & 12,02 & -52 \\
\hline 10 & 16,86 & -60 \\
\hline 11 & 21,78 & -69 \\
\hline 12 & 16,56 & -59 \\
\hline & & \\
\hline
\end{tabular}

\begin{tabular}{|l|l|l|}
\hline 13 & 17,73 & -62 \\
\hline 14 & 20,11 & -65 \\
\hline 15 & 23,33 & -74 \\
\hline 16 & 27,10 & -77 \\
\hline 17 & 24,38 & -76 \\
\hline 18 & 22,46 & -74 \\
\hline
\end{tabular}

Tabel 6 Hasil pengukuran signal level kondisi penghalang dinding

\begin{tabular}{|c|c|c|}
\hline Ruang & $\begin{array}{c}\text { Jarak Antara } \\
\text { AP dan } \\
\text { Client (m) }\end{array}$ & $\begin{array}{l}\text { Hasil Pengukuran } \\
\text { (dBm) }\end{array}$ \\
\hline \multirow{6}{*}{ R1 } & 6,51 & -62 \\
\hline & 8,51 & -64 \\
\hline & 10,51 & -66 \\
\hline & 6,96 & -62 \\
\hline & 8,86 & -64 \\
\hline & 10,79 & -66 \\
\hline \multirow{3}{*}{ R2 } & 3,53 & -55 \\
\hline & 4,30 & -59 \\
\hline & 5,70 & -61 \\
\hline \multirow{5}{*}{ R3 } & 3,51 & -47 \\
\hline & 3,89 & -57 \\
\hline & 5,09 & -59 \\
\hline & 6,68 & -62 \\
\hline & 5,70 & -60 \\
\hline \multirow{6}{*}{ R4 } & 6,44 & -61 \\
\hline & 7,58 & -64 \\
\hline & 8,26 & -64 \\
\hline & 9,18 & -65 \\
\hline & 10,15 & -65 \\
\hline & 10,91 & -67 \\
\hline \multirow{6}{*}{ R5 } & 9,82 & -65 \\
\hline & 11,51 & -70 \\
\hline & 11,10 & -69 \\
\hline & 12,62 & -72 \\
\hline & 12,57 & -70 \\
\hline & 13,93 & -76 \\
\hline \multirow{2}{*}{ R6 } & 13,66 & -73 \\
\hline & 14,40 & -79 \\
\hline
\end{tabular}

Tabel 7 Hasil pengukuran signal level kondisi penghalang lantai

\begin{tabular}{|c|c|c|}
\hline Titik & $\begin{array}{c}\text { Jarak Antara } \\
\text { AP dan Client } \\
\mathbf{( m )}\end{array}$ & $\begin{array}{c}\text { Hasil } \\
\text { Pengukuran } \\
\mathbf{( d B m})\end{array}$ \\
\hline 1 & 26,24 & -83 \\
\hline 2 & 21,54 & -72 \\
\hline 3 & 17 & -66 \\
\hline 4 & 12,80 & -65 \\
\hline 5 & 9,43 & -57 \\
\hline 6 & 8 & -54 \\
\hline 7 & 9,43 & -59 \\
\hline 8 & 10,67 & -61 \\
\hline 9 & 13,74 & -66 \\
\hline 10 & 17,72 & -66 \\
\hline
\end{tabular}




\begin{tabular}{|l|c|l|}
\hline 11 & 22,11 & -72 \\
\hline 12 & 17 & -66 \\
\hline 13 & 17,72 & -71 \\
\hline 14 & 19,72 & -71 \\
\hline 15 & 22,67 & -74 \\
\hline 16 & 26,24 & -85 \\
\hline 17 & 23,74 & -74 \\
\hline 18 & 22,11 & -72 \\
\hline
\end{tabular}

4.3 Hasil Perbandingan Perhitungan dan Pengukuran Signal Level

Perbandingan antara perhitungan dan pengukuran signal level menghasilkan selisih dalam bentuk grafik yang ditunjukkan pada Gambar 1, 2, dan 3.

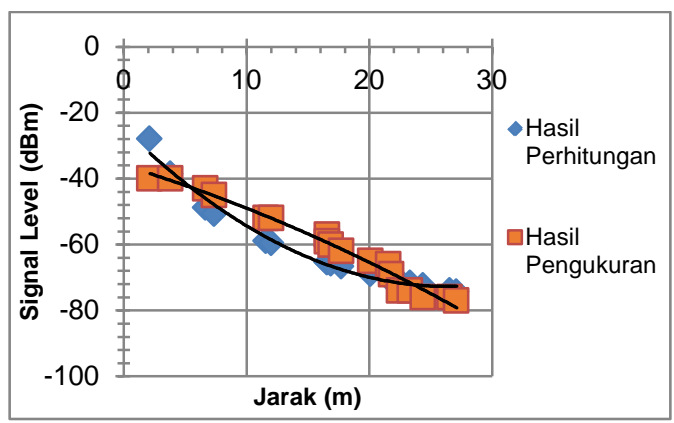

Gambar 1 Grafik hasil perbandingan perhitungan dan pengukuran signal level kondisi tanpa penghalang

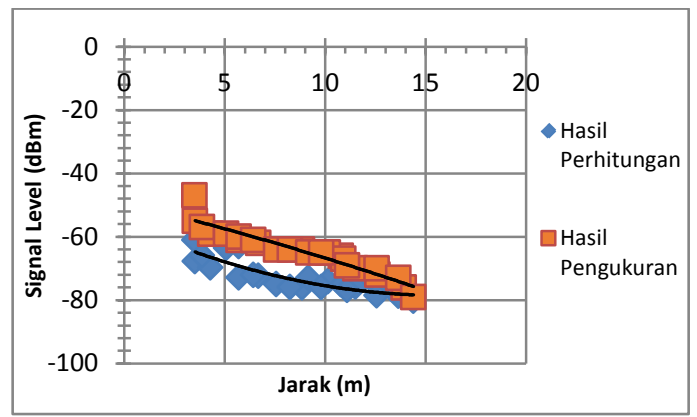

Gambar 2 Grafik hasil perbandingan perhitungan dan pengukuran signal level kondisi penghalang dinding

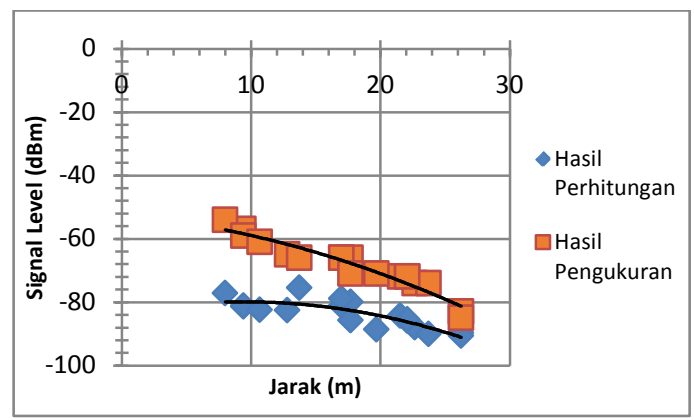

Gambar 3 Grafik hasil perbandingan perhitungan dan pengukuran signal level kondisi penghalang lantai
Dari Gambar 1,2, dan 3 terlihat bahwa hasil pengukuran lebih baik dibandingkan dengan hasil perhitungan. Itu disebabkan oleh perhitungan yang diasumsikan menggunakan nilai koefisien transmisi dinding sebesar 0,3 dan koefisien transmisi lantai sebesar 0,17. Dimana untuk koefisen dinding maupun lantai belum ada nilai pasti untuk mengukur AP yang digunakan. Hal ini menyebabkan hasil perhitungan masih kurang tepat.

\subsection{Hasil Pengukuran Throughput}

Pada pengukuran throughput menggunakan software Axence NetTools perangkat client. Hasil pengukuran throughput dengan 3 kondisi pemodelan propagasi indoor ditunjukkan pada Tabel 8,9 , dan 10 berikut.

Tabel 8 Hasil pengukuran throughput kondisi tanpa penghalang

\begin{tabular}{|c|c|c|}
\hline Titik & $\begin{array}{c}\text { Jarak Antara } \\
\text { Access Point } \\
\text { dan Client (m) }\end{array}$ & $\begin{array}{c}\text { Pengukuran } \\
\text { Throughput } \\
\text { (Mbps) }\end{array}$ \\
\hline 1 & 26,54 & 2,02 \\
\hline 2 & 21,55 & 3,36 \\
\hline 3 & 16,56 & 5,44 \\
\hline 4 & 11,59 & 5,55 \\
\hline 5 & 6,67 & 6,65 \\
\hline 6 & 2,12 & 8,05 \\
\hline 7 & 3,80 & 6,67 \\
\hline 8 & 7,38 & 6,21 \\
\hline 9 & 12,02 & 5,53 \\
\hline 10 & 16,86 & 4,66 \\
\hline 11 & 21,78 & 2,93 \\
\hline 12 & 16,56 & 5,10 \\
\hline 13 & 17,73 & 4,30 \\
\hline 14 & 20,11 & 3,63 \\
\hline 15 & 23,33 & 2,16 \\
\hline 16 & 27,10 & 1,78 \\
\hline 17 & 24,38 & 2,12 \\
\hline 18 & 22,46 & 2,69 \\
\hline
\end{tabular}

Tabel 9 Hasil pengukuran throughput kondisi penghalang dinding

\begin{tabular}{|c|c|c|}
\hline \multirow{4}{*}{ Ruang } & $\begin{array}{c}\text { Jarak Antara } \\
\text { AP dan } \\
\text { Client (m) }\end{array}$ & $\begin{array}{c}\text { Pengukuran } \\
\text { Throughput } \\
\text { (Mbps) }\end{array}$ \\
\hline \multirow{4}{*}{ R1 } & 6,51 & 4,83 \\
\cline { 2 - 3 } & 8,51 & 3,74 \\
\cline { 2 - 3 } & 10,51 & 2,88 \\
\cline { 2 - 3 } & 6,96 & 4,50 \\
\cline { 2 - 3 } & 8,86 & 3,72 \\
\hline \multirow{3}{*}{ R2 } & 10,79 & 2,69 \\
\cline { 2 - 3 } & 3,53 & 6,32 \\
\cline { 2 - 3 } & 4,30 & 5,63 \\
\hline \multirow{2}{*}{ R3 } & 5,70 & 5,03 \\
\cline { 2 - 3 } & 3,51 & 6,65 \\
\hline
\end{tabular}




\begin{tabular}{|c|c|c|}
\hline \multirow{4}{*}{} & 5,09 & 5,51 \\
\cline { 2 - 3 } & 6,68 & 4,58 \\
\hline \multirow{4}{*}{ R4 } & 5,70 & 5,34 \\
\cline { 2 - 3 } & 6,44 & 4,96 \\
\cline { 2 - 3 } & 7,58 & 4,25 \\
\cline { 2 - 3 } & 8,26 & 3,90 \\
\cline { 2 - 3 } & 9,18 & 3,66 \\
\cline { 2 - 3 } & 10,15 & 3,31 \\
\hline \multirow{4}{*}{ R5 } & 10,91 & 2,45 \\
\cline { 2 - 3 } & 9,82 & 3,33 \\
\cline { 2 - 3 } & 11,51 & 1,52 \\
\cline { 2 - 3 } & 11,10 & 2,33 \\
\cline { 2 - 3 } & 12,62 & 1,36 \\
\cline { 2 - 3 } & 12,57 & 1,41 \\
\hline \multirow{4}{*}{ R6 } & 13,93 & 0,79 \\
\cline { 2 - 3 } & 13,66 & 1,03 \\
\hline
\end{tabular}

Tabel 10 Hasil pengukuran throughput kondisi penghalang lantai

\begin{tabular}{|c|c|c|}
\hline Titik & $\begin{array}{c}\text { Jarak Antara } \\
\text { AP dan Client } \\
\mathbf{( m )}\end{array}$ & $\begin{array}{c}\text { Pengukuran } \\
\text { Throughput } \\
\text { (Mbps) }\end{array}$ \\
\hline 1 & 26,24 & 0,56 \\
\hline 2 & 21,54 & 0,82 \\
\hline 3 & 17 & 1,13 \\
\hline 4 & 12,80 & 1,31 \\
\hline 5 & 9,43 & 1,80 \\
\hline 6 & 8 & 2,28 \\
\hline 7 & 9,43 & 1,64 \\
\hline 8 & 10,67 & 1,41 \\
\hline 9 & 13,74 & 1,14 \\
\hline 10 & 17,72 & 0,90 \\
\hline 11 & 22,11 & 0,80 \\
\hline 12 & 17 & 1,05 \\
\hline 13 & 17,72 & 0,86 \\
\hline 14 & 19,72 & 0,83 \\
\hline 15 & 22,67 & 0,71 \\
\hline 16 & 26,24 & 0,44 \\
\hline 17 & 23,74 & 0,64 \\
\hline 18 & 22,11 & 0,71 \\
\hline & & \\
\hline
\end{tabular}

Berdasarkan Tabel 8, 9, dan 10 terlihat hasil pengukuran throughput mengalami penurunan berbanding lurus dengan semakin menjauhnya jarak pengukuran. Hal ini disebabkan oleh adanya faktor propagasi yaitu adanya pembelokan sinyal, pemantulan sinyal, dan juga penyerapan sinyal.

\subsection{Pengukuran Coverage Area}

Pengukuran coverage area pada salah satu lantai gedung yaitu lantai 2 yang mewakili seluruh lantai pada gedung. Coverage maksimum dari sebuah AP pada gedung Dishubkominfo didapatkan dengan cara mengukur signal level menggunakan software Ekahau HeatMapper. Berdasarkan software Ekahau
HeatMapper kualitas coverage warna dalam software Ekahau HeatMapper yang dapat dilihat pada Tabel 11.

Tabel 11 Kuat sinyal coverage area wireless pada software Ekahau HeatMapper [7].

\begin{tabular}{|c|c|c|}
\hline $\begin{array}{c}\text { Warna } \\
\text { coverage }\end{array}$ & $\begin{array}{c}\text { Kuat sinyal } \\
(\mathrm{dBm})\end{array}$ & $\begin{array}{c}\text { Kualitas } \\
\text { sinyal }\end{array}$ \\
\hline & $-40 \mathrm{~s} / \mathrm{d}-50$ & Baik \\
\hline & $-50 \mathrm{~s} / \mathrm{d}-60$ & $\begin{array}{c}\text { Kurang } \\
\text { baik }\end{array}$ \\
\hline & $-60 \mathrm{~s} / \mathrm{d}-85$ & Kurang \\
\hline & $-85 \mathrm{~s} / \mathrm{d}-100$ & Buruk \\
\hline
\end{tabular}

Gambar 4 merupakan hasil pengukuran coverage area dengan jumlah titik pengukuran mencapai 68 titik pada salah satu lantai gedung Dishubkominfo.

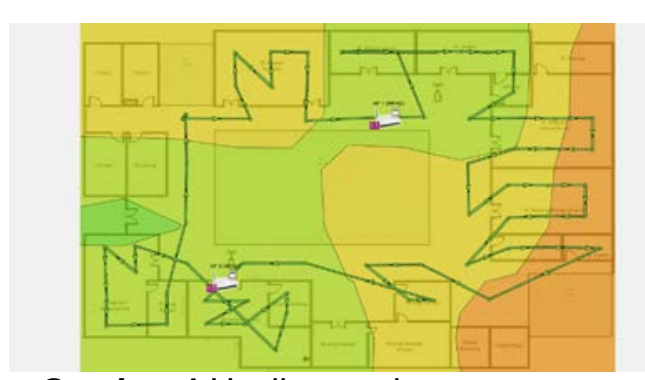

\section{Gambar 4 Hasil pengukuran coverage}

Dari Gambar 4 terlihat area yang ter-cover sinyal wifi sudah mencakup hampir seluruh ruangan pada lantai 2 gedung. Hanya saja pada ruangan sebelah timur belum tercoverage secara optimal disebabkan faktor jarak dan faktor propagasi.

\section{KESIMPULAN}

Hasil dari perhitungan dan pengukuran signal level memperlihatkan hasil pengukuran lebih baik dibandingkan dengan hasil perhitungan. Itu disebabkan oleh perhitungan yang diasumsikan menggunakan nilai koefisien transmisi dinding sebesar 0,3 dan koefisien transmisi lantai sebesar 0,17. Dimana untuk koefisen dinding maupun lantai belum ada nilai pasti untuk mengukur AP yg digunakan. Hal ini menyebabkan hasil perhitungan masih kurang tepat. Untuk nilai signal level pengukuran tertinggi yang diperoleh adalah sekitar $-40 \mathrm{dBm}$, sedangkan signal level terendah adalah sekitar $-85 \mathrm{dBm}$.

Hasil pengukuran menunjukkan throughput maksimal mencapai 8,05 Mbps 
sedangkan untuk throughput terendah rata-rata mencapai 0,44 Mbps.

Hasil dari pengukuran coverage yang diperoleh menunjukkan daya pancar AP belum maksimal. Penyebabkan adalah faktor struktur bangunan dan ketebalan dinding. Perlu adanya penambahan AP pada bagian timur gedung agar tercoverage secara maksimal.

\section{DAFTAR PUSTAKA}

[1]. Feryawan, A. Analisis Karakteristik Propagasi Indoor WLAN IEEE 802.11n Untuk Lingkungan Laboratorium Jurusan Teknik Elektro Universitas Udayana. Skripsi. Badung : Universitas Udayana. 2013.

[2]. Singh, J. Quality of Service in Wireless LAN Using OPNET Modeler. Patiala : Thapar University. 2009.

[3]. IEEE. Wireless LAN Medium Access Control (MAC) and Physical Layer (PHY) specifications Further Higher Data Rate Extension in the $2.4 \mathrm{GHz}$ Band. United State : IEEE. 2003.

[4]. Khasanah, Nur dkk. 2010. Visualisasi Propagasi Gelombang Indoor Pada Wi-Fi $2,4 \mathrm{GHz}$. Surabaya : Fakultas Poltek Negeri Surabaya. 2010.

[5]. Gunantara N, Hendrantoro G. Optimasi Permasalahan Jamak (MOO) Lintas Lapisan Untuk Pemilihan Relay Pada Sistem Komunikasi Nirkabel AdHoc dan Kooperatif. Disertasi. Surabaya : ITS. 2014.

[6]. Setio Dewo, E. Bandwidth dan Throughput. Semarang. Copyright 2003 IImuKomputer.com. 2003.

[7]. https://www.ubnt.com/unifi/unifi-ap/, diakses tanggal 5 september 2017.

[8]. https://www.ekahau.com/products/hea tmapper/faq/, diakses tanggal 5 september 2017. 